\title{
Research on tunnel bearing structure safety under high geostress
}

\author{
LIU Ning ${ }^{a}$, CHEN Jian Lin ${ }^{b}$, CHU Weijiang ${ }^{c}$ and CHEN Ping Zhi ${ }^{d}$ \\ PowerChina Huadong Engineering Corporation Limited, Hangzhou, China \\ aliu_n@ecidi.com, ${ }^{\mathrm{b}} \mathrm{C}$ enjl@ecidi.com, ${ }^{\mathrm{C}} \mathrm{C}$ uwj@ecidi.com, ${ }^{\mathrm{d}} \mathrm{Chenpz@ecidi.com}$
}

Keywords: high geostress; bearing structure; lining; seepage; fracture

Abstract. The underground water level of diversion tunnel is so high, that the power station in run-time will suffer enormous external hydraulic pressure, especially the marble show time dependent failure phenomenon, and increase the risk in run- time. For this reason, the reinforced concrete lining is adopted, and combine with the primary support and the consolidation grouting to form a composite bearing structure to ensure the stability of surrounding rock. According to the mechanism of lining structure and grouting on the surrounding rock stability, the importance of the composite bearing structure for the long-term stability of tunnel was revealed. By the three- dimensional seepage field analysis to reveal the importance of the relief pressure hole for the lining structure, and the pressure of lining edge is determined. The calculation results show that, in accordance with the existing design scheme, the whole stability of the structure can be guaranteed.

\section{Introduction}

During the construction of the long deep buried tunnels, we followed the principle that the stability of the surrounding rock should primarily rely on the self-supporting capacity of the surrounding rock itself. The surrounding rock was the main load-bearing structure, and measures including anchor support and secondary high pressure consolidation grouting were applied to reinforce the surrounding rock, so that the surrounding rock and the anchor support become a unified complex, and served as a combination load bearing structure (see Fig.1). This ensured the stability of the surrounding rock in the loose circle on the internal surface of tunnel, and provided triaxial confining pressure on the surrounding rock[1]. In this way, the surrounding rock under the triaxial confining pressure itself was used to bear the geostress caused by tunnel excavation, as well as the high groundwater pressure, thereby ensuring the safety and stability of the deep buried tunnels under high external water pressure.

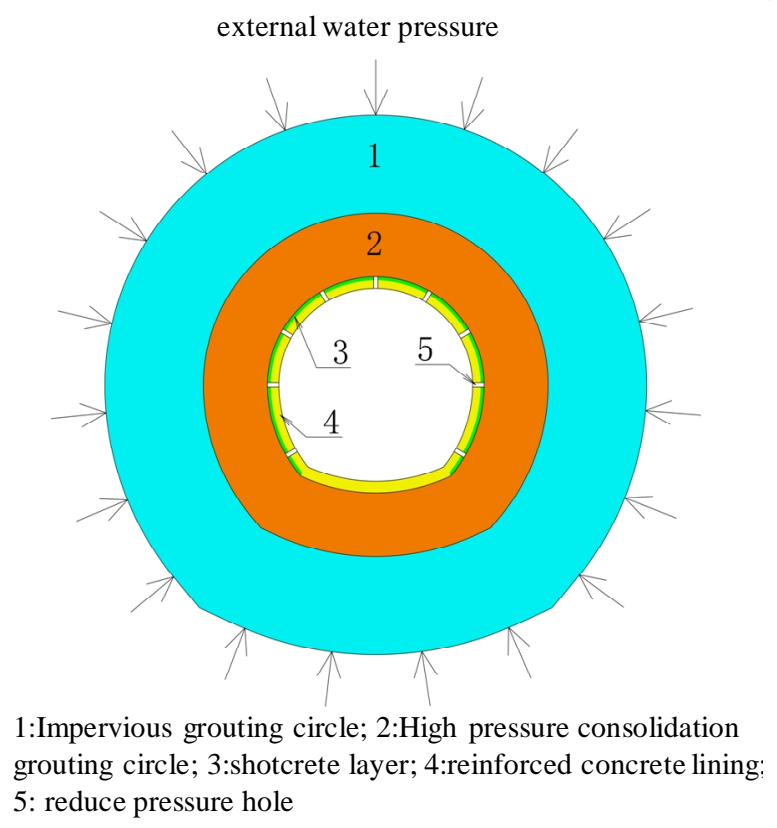

Fig.1 Combination load bearing structure

In practice, when designing the support, the method of dynamic design was followed. According to the geological conditions and construction conditions revealed in the actual tunnel excavation, the 
pre-designed rock classification system and support parameters were used as a reference only. Combined with on-site prototype monitoring and geophysical exploration data, field test results on new materials and new technologies, and analysis of surrounding rock fracture and damage in deep depth, the support structure was actively optimized[2].

\section{Selecting the Support Unit}

Selecting the Bolt. Selecting the appropriate type of support unit required full understanding of its mechanical properties, as well as the advantages and disadvantages of the support unit itself. For specific modes of rock instability, the choice of support should be made to fully utilize its advantages and avoid its disadvantages, in order to avoid conditions unfavorable to the stability of surrounding rock. For example, the water swelling bolt belongs to friction-type anchorage bodies. Namely, it relies on the friction between the tunnel surrounding and the anchorage body to provide support. Its greatest advantage is that it can be quickly installed, which suits the requirement of rapid support in the excavation of Jinping II tunnel segments with high rock burst risk and a large cross section. However, these tunnel segments also had the prominent problem of surrounding rock fracture. Under this condition, if a water swelling bolt is used, the surface support and the anchoring force at the deep water-swelling segment need to work together to maintain the stability of fractured rock in the shallow layer. This poses challenging demands on the strength of the surface support, the bearing plate, and the anchoring force of the water-swelling bolt. These 3 aspects are the key steps to stability control of surrounding rock in deep, long, large-diameter tunnels.

For the diversion tunnel project of Jinping II Hydropower Station, after comparing the form and properties of different anchorage bodies, taking factors such as the speed, difficulty, and efficiency of the on-site construction into consideration, and through continuous testing, the water swelling bolt, the regular mortar bolt and the expanding-shell prestressed bolt were selected as the main anchorage bodies to be used on the construction sites (see Fig.2). To choose among these 3 types of anchorage bodies in principle depends on the mechanical properties of marbles under high stress, and the requirement for stability control of the on-site surrounding rock, and is also affected by actual application conditions of the sites. Through field tests and assessment on the overall effects, it was ultimately determined that the water swelling anchorage bodies would be used as the random bolt, and the bolt for rock burst prevention and control; the local expanding-shell prestressed anchorage bodies would be used as the immediate permanent support; and the regular mortar anchorage bodies would be used as the lagged local permanent support.

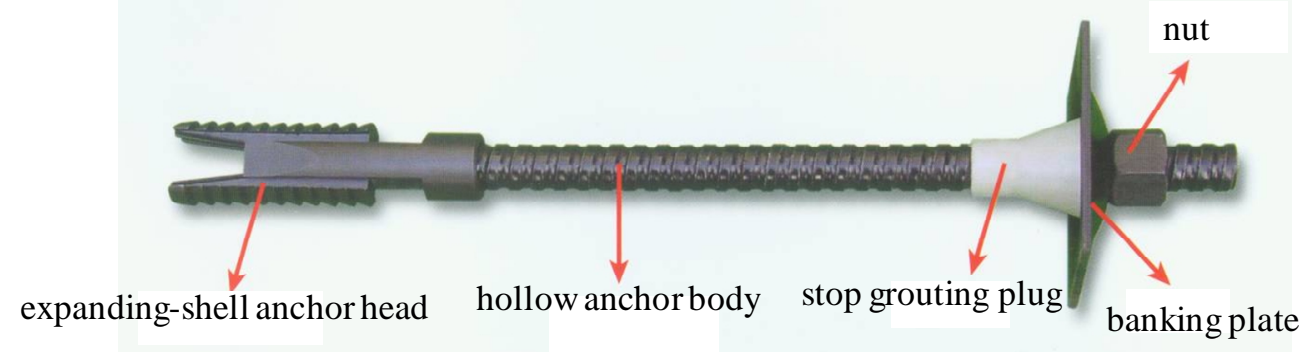

Fig.2 Expanding-shell prestressed bolt

Selecting the Shotcrete. Due to the prominent surrounding rock stability problem, the high risk of rock burst under high geostress, and other issues in deep, long, large-diameter hydraulic tunnels, we carried out on-site tests on various new types of shotcrete. From the results of these tests, we determined to use silica fume and steel fiber double reinforced concrete, nano steel fiber concrete, nano organic imitation steel fiber reinforced concrete, and plain hanging shotcrete as the main types of supporting shotcrete(see Fig.3, 4). For the general high-geostress tunnel segments, by adding nanomaterials to the shotcrete, the thickness of the primary projection was improved, and the shotcrete hardened quicker. In this way, the deformation, relaxation, and failure of the surrounding rock could be controlled. In tunnel segments with rock burst, powerful supporting measures needed to be taken to control rock failure. Under the premise of using the anchor support system, the shotcrete with the best 
performance, namely the silica fume and steel fiber double reinforced concrete, was used as the main supporting material, in order to ensure surrounding rock stability and construction safety. In addition, plain hanging shotcrete was subsequently applied to strengthen the support.

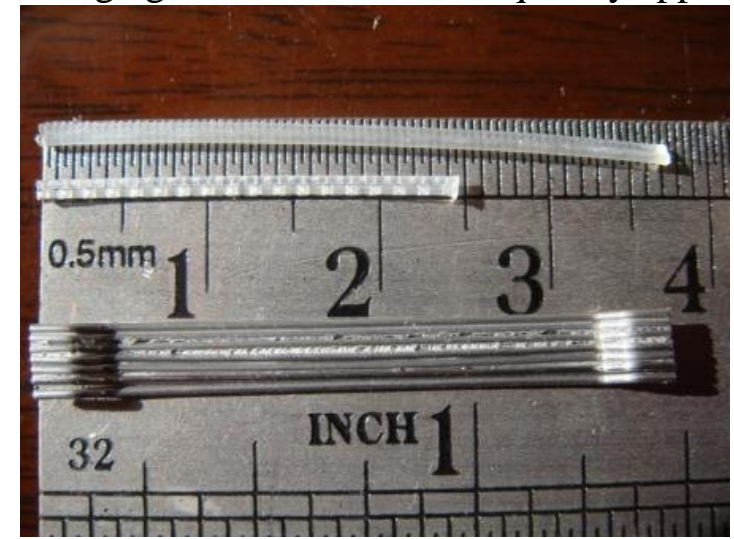

Fig.3 Nano steel fiber

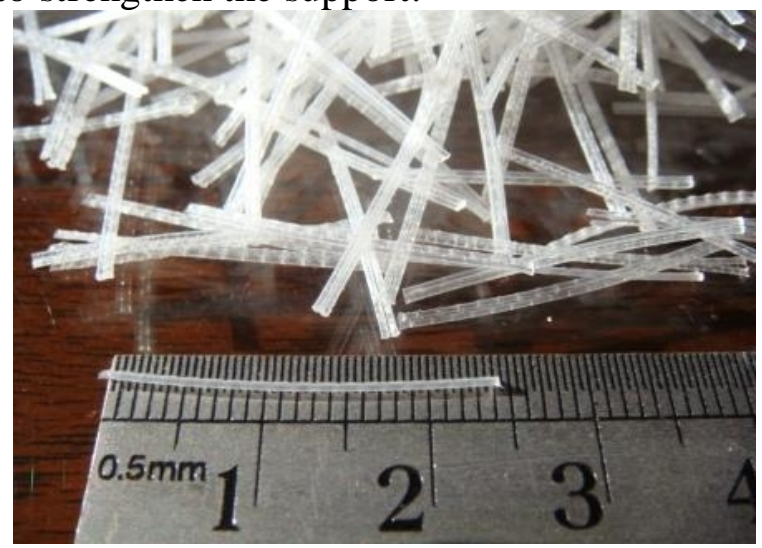

Fig.4 Nano organic imitation steel fiber

\section{High-pressure Seepage-proof Consolidation Grouting}

In the process of diversion tunnel construction, based on the actual geological conditions and the engineering requirements, we carefully examined the consolidation grouts for different surrounding rock and classified them into 4 types. The first type, consolidation grouting for fractured surrounding rock, belongs to regular grouting. Its purpose is mainly to improve the mechanical properties of the rock mass, increase its load bearing capacity, and improve the impermeability of the surrounding rock. The second type is consolidation grouting for karst tunnel segments, used for preventing internal water from leaking out after completing the backfilling of concrete or mortar in the cavern. The third type is high-pressure seepage-proof consolidation grouting. It is the primary means of counteracting the high external water pressure around the tunnel, controlling the stability of the seepage and reducing the amount of seepage. The fourth type is shallow consolidation grouting, which is designed specifically to target the widespread occurrence of relaxation, fracture, swelling, and failure of the shallow layer of brittle marble tunnels under high stress. Shallow consolidation grouting combined with secondary reinforced concrete lining provides a triaxial pressure condition to the deep surrounding rock. This increases the load bearing capacity of the surrounding rock, and meanwhile improves their seepage-proof performance.

\section{The Lining Structure}

Given the fact that under high geostress, fracture induced damages to surrounding rock are widespread[3], and have a time effect[4], the long-term stability and safety of anchor-plate retention cannot be guaranteed. Thus, in deep buried tunnel segments with high geostress, reinforced concrete lining was combined with shallow consolidation grouting to reinforce the surrounding rock(see Fig.5). This ensured that the supporting structure and the surrounding rock bore forces synergistically, and effectively transferred the load, and internal and external water pressure on the surrounding rock. Meanwhile the surrounding rock was closed, and high confining pressure applied to the surrounding rock, preventing the development of internal rock mass relaxation, and improving the peak strength and residual strength of the surrounding rock under triaxial confining pressure[5]. In this way, the stability of the surrounding rock surrounding the diversion tunnels was ensured. 


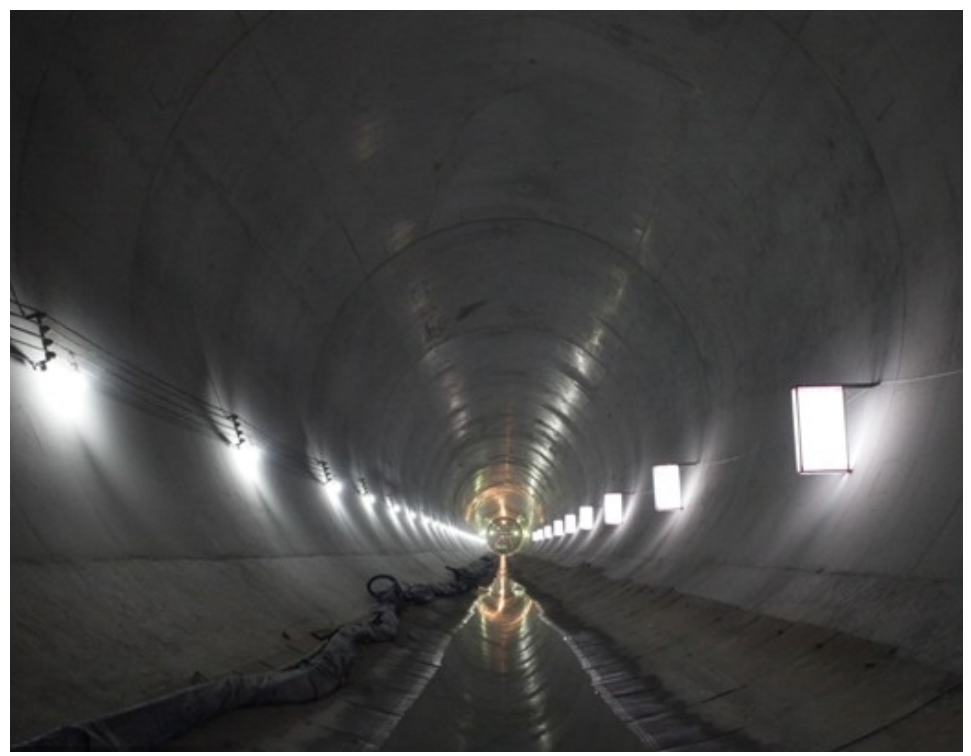

Fig.5 Diversion tunnel face before operation

\section{Conclusions}

The ability of deep, large-diameter hydraulic tunnels to bear external water pressure is rather weak. In order to ensure the long-term safe operation of these tunnels, a drainage tunnel was constructed between the diversion tunnel and auxiliary tunnel for long-term discharge of groundwater, thereby reducing the overall external water pressure along the axis of the diversion tunnel. In extreme conditions such as rainstorms, external water pressure rises sharply over a short amount of time. To handle this problem, consolidation grouting was applied to the entire length and the entire cross section of the diversion tunnel to form an impermeable ring. In addition, system decompression holes were arranged in the lining structure in order to rapidly balance and discharge external water, so that the external water pressure on the outer margin of the lining was maintained within the allowable range of its design. This ensured that the lining structure would not lose stability and collapse due to excessive external water pressure.

\section{References}

[1] Lau J S O, Chandler N A. Innovative laboratory testing. International Journal of Rock Mechanics and Mining Sciences, Vol. 41(2004), p.1427.

[2] Zhang Chunsheng, Chen Xiangrong, Hou Jing, et al. Study of mechanical behavior of deep-buried marble at Jinping II hydropower station. Chinese Journal of Rock Mechanics and Engineering, Vol. 29(2010), p.1999.

[3] Potyondy D O. Simulating stress corrosion with a bonded-particle model for rock. International Journal of Rock Mechanics and Mining Sciences, Vol. 44(2007), p.677-691.

[4] Schmidtke R H, Lajtai E Z. The long-term strength of Lac du Bonnet granite. International Journal of Rock Mechanics and Mining Sciences and Geomechanics Abstracts, Vol. 22(1985), p.461.

[5] Cai M, Kaiser P K. Assessment of excavation damaged zone using a micromechanics model. Tunnelling and Underground Space Technology, Vol. 20(2005), p.301. 